\title{
Interrelation of heart rate and autonomic activity in asymptomatic men with unobstructed coronary arteries Studies with atrial pacing, adrenaline infusion, and autonomic blockade
}

\author{
P TAGGART, R DONALDSON, J GREEN, S P JOSEPH, H B KELLY, \\ J MARCOMICHELAKIS, D NOBLE, J WHITE \\ From the Department of Cardiology, The Middlesex Hospital, London; The Royal Air Force Central Medical \\ Establishment; and The University Laboratory of Physiology, Oxford
}

SUMMARY We have extended our observations on asymptomatic men with abnormal resting electrocardiograms showing changes indistinguishable from those of myocardial ischaemia but with normal coronary arteriograms. In the present investigation we aimed to separate the effects of heart rate alone from those of the sympathetic nervous system. We therefore studied the effects of atrial pacing alone, pacing and adrenaline infusion combined, pacing after beta-blockade, and pacing after beta-blockade plus atropine.

Twenty asymptomatic men, aged 17 to 57, were investigated. All were shown to have unobstructed coronary arteries and normal left ventricular angiograms. Echocardiographic findings were normal. Sixteen had flat or inverted $T$ waves in the lateral leads (designated "T"), two had ST depression (designated "ST"), and two had mixed patterns.

$T$ wave abnormalities and, to a lesser extent, ST changes returned to normal or regressed after an overnight rest in hospital. Subsequent atrial pacing to 160 /minute reproduced or increased the respective abnormalities. When adrenaline was infused in low doses just sufficient to produce discernible effects on the ST-T segment (between 0.024 and $0.091 \mu \mathrm{g} / \mathrm{kg}$ per min) and atrial pacing was repeated, the effect of the latter was enhanced. Both adrenaline and pacing influenced the ST-T segment in the same direction. Intravenous propranolol $(0.2 \mathrm{mg} / \mathrm{kg})$ blocked the effect of adrenaline and its synergistic effect with pacing but exerted little if any influence on the effect of pacing alone. Atropine given intravenously after propranolol $(0.04 \mathrm{mg} / \mathrm{kg})$ reduced the effect of atrial pacing on the ST-T configuration.

Treadmill exercise tests were positive in nine and borderline in one. After beta-blockade (oral oxprenolol), all tests were negative. As beta-blockade did not prevent pacing-induced ST depression but normalised the false positive exercise test, the latter does not appear to be rate related but more probably the result of the direct influence of catecholamines. Isolated $T$ wave changes and ST depression in the resting electrocardiogram differ in that they are influenced both by heart rate and catecholamines acting synergistically.

We have reported observations on asymptomatic men with abnormal electrocardiograms showing changes indistinguishable from those of myocardial ischaemia but with normal coronary arteriograms. ${ }^{1}$ An altered response to autonomic activity was shown: whereby these changes could be readily manipulated by measures designed to influence sympathetic activity, such as tranquillity, intravenous infusion of adrenaline,

Accepted for publication 28 August 1981 and beta-adrenergic blockade. Since changes in heart rate as well as sympathetic behaviour may be relevant, however, acting either independently or in combination, it seemed appropriate to attempt to evaluate the effect of each separately and the interplay between the two on the electrocardiographic configuration in a similar group of asymptomatic men.

We have accordingly recorded the electrocardiogram during atrial pacing, intravenous adrenaline infusion, and the combination of the two, both with- 
out medication and after propranolol and also after propranolol together with atropine. We have also included maximal treadmill exercise tests without medication and after oxprenolol to allow comparisons to be drawn between the ST-T changes induced during the above procedures and during exercise.

\section{Subjects and methods}

The subjects were 20 men aged 17 to 57 (mean 35) whose professional livelihood was threatened by abnormalities indistinguishable from those of myocardial ischaemia on a routine resting electrocardiogram. All were asymptomatic expect one, an 18year-old with a mildly depressed sternum who presented with undue dyspnoea and tachycardia on exertion; these symptoms only occurred on that occasion, and he showed excellent effort tolerance on treadmill exercise testing. All the subjects were referred because of abnormal resting electrocardiograms. Physical examination disclosed nothing other than the depressed sternum described and mild hypertension in two individuals one of whom was taking a diuretic. None had the Wolff-Parkinson-White syndrome or other conditions known to be associated with a false positive exercise test. The nature and purpose of the tests were explained to each subject.

\section{EXERCISE TESTING}

Maximal treadmill exercise tests were carried out twice on each subject, before and one and a half hours after an oral dose of $80 \mathrm{mg}$ oxprenolol. The multistage protocol of Bruce was adopted ${ }^{2}$ using the Avionics monitor model 3000 with computer programmer P.100 and recording $3 \mathrm{CM}$ leads positioned according to the praecordial leads showing the most conspicuous abnormalities. CM5 was included in each case. The end point chosen was fatigue and no test had to be terminated prematurely. Tests were classed as positive, negative, or borderline. ${ }^{1}$

\section{ECHOCARDIOGRAMS}

Echocardiograms were performed on all subjects using the Smith-Kline Echoline 20A and 2.25 transducer focused at $7.5 \mathrm{~cm}$ recording on a Cambridge fibreoptic recorder. The technique was as previously described ${ }^{1}$ but a septal to posterior free left ventricular wall ratio of 1.3 rather than 1.5 was taken as the upper limit of normal.

\section{CARDIAC CATHETERISATION}

Left heart catheterisation and coronary angiography were carried out using the Sones or Judkins technique. Single plane left ventricular cineangiography was performed in the right anterior oblique position at $30^{\circ}$ at $\mathbf{4 0}$ frames per second.

\section{PACING/INFUSION STUDIES}

A $5 \mathrm{~F}$ bipolar pacing electrode was positioned in the ${ }^{\tau}$ high right atrium via the right femoral vein. Pacing $\vec{\Rightarrow}$ was carried out with a $1 \mathrm{~ms}$ pulse width at twice the diastolic threshhold.

Freshly diluted adrenaline was infused into a lefw. arm vein by a Harvard constant infusion pump (model 975) at four dosage rates: 0.024, 0.047, 0.091 and $0.18 \mu \mathrm{g} / \mathrm{kg}$ per $\mathrm{min}$.

A three-channel electrocardiogram was recorded 5 using the lead positions selected for the exercise tests. $\overrightarrow{\mid}$

The electrocardiogram was recorded for 10 secondsw at a time; at rest and during atrial pacing at rates of $100,120,140$, and 160 per min each, or to the highes rate where 1:1 atrioventricular conduction was ${ }^{2}$ achieved. Adrenaline was then infused for four minutes at the lowest dose rate and the electrocardiose gram recorded before and during incremental atria $B$ pacing. The infusion was then discontinued for three minutes before the next dose. In this way recordingsy reflected pacing alone, adrenaline alone, and the two in combination at different infusion rates. Highe doses were not used if a clear-cut effect was produced by a lower one.

In 10 patients propranolol was then administered intravenously $(0.2 \mathrm{mg} / \mathrm{kg})$ and the procedure was repeated using the highest dosage of adrenaline thas had been administered. These 10 patients were therp given intravenous atropine $(0.04 \mathrm{mg} / \mathrm{kg})$ and pacing was repeated without adrenaline infusion.

\section{Results}

\section{RESTING ELECTROCARDIOGRAMS}

Sixteen subjects showed flat or inverted $T$ waves in either the inferolateral or anterolateral leads in thei resting electrocardiogram, two had ST segment? depression, and two had mixed patterns (Table).

\section{ECHOCARDIOGRAMS}

No subject with any echocardiographic abnormality was included in the study.

\section{EXERCISE TESTS}

Treadmill tests fulfilled the criteria as positive fon myocardial ischaemia in nine, they were borderline in one, and negative in 10 when conducted without medication. When repeated after oxprenolol they were negative in all 20 . Of the nine positive tests before oxprenolol, five were already positive and two were borderline at a fairly early stage when the hearof rate had reached the maximum rate achieved during the tests on oxprenolol (Table). Maximum heart rates without medication and after oxprenolol were 184 12.8 and $130 \pm 11.9$, respectively.

One subject, case 9 , had a positive test both before 
Table Individual data on 20 subjects in study

\begin{tabular}{|c|c|c|c|c|c|c|}
\hline \multirow[t]{2}{*}{ Case No. } & \multirow[t]{2}{*}{ Age $(y)$} & \multirow[t]{2}{*}{ Electrocardiogram } & \multicolumn{3}{|c|}{ Treadmill exercise } & \multirow[t]{2}{*}{ Pacing/infusion } \\
\hline & & & $\begin{array}{l}\text { No medication } \\
\text { MHR }\end{array}$ & At MHR blocked & $\begin{array}{l}\text { Oxprenolol } \\
M H R\end{array}$ & \\
\hline $\begin{array}{l}1 \\
2 \\
3 \\
4 \\
5 \\
6 \\
7 \\
8 \\
9\end{array}$ & $\begin{array}{l}53 \\
52 \\
18 \\
17 \\
28 \\
42 \\
43 \\
44 \\
30\end{array}$ & $\begin{array}{l}\text { ST } \\
\text { ST } \\
T \\
T \\
T \\
T \\
T \\
T \\
T \\
T\end{array}$ & $\begin{array}{l}150+ \\
190+ \\
170- \\
180- \\
190+ \\
180-\mathrm{t} \\
190+ \\
185+ \\
200+\end{array}$ & $\begin{array}{l}- \\
+ \\
- \\
\overline{-} \\
\text { B } \\
- \\
+ \\
\text { B } \\
+\end{array}$ & $\begin{array}{l}100- \\
125- \\
130- \\
130- \\
110- \\
130- \\
160- \\
130- \\
(135- \\
(150+)\end{array}$ & $\begin{array}{l}\downarrow \\
\downarrow \\
\downarrow \\
\downarrow\end{array}$ \\
\hline $\begin{array}{l}10 \\
11 \\
12 \\
13 \\
14 \\
15 \\
16 \\
17 \\
18 \\
19 \\
20\end{array}$ & $\begin{array}{l}57 \\
39 \\
47 \\
20 \\
18 \\
41 \\
40 \\
29 \\
34 \\
17 \\
31\end{array}$ & $\begin{array}{l}\mathrm{T} \\
\mathrm{T} / \mathrm{ST} \\
\mathrm{ST} / \mathrm{T} \\
\mathrm{T} \\
\mathrm{T} \\
\mathrm{T} \\
\mathrm{T} \\
T \\
\mathrm{~T} \\
\mathrm{~T} \\
\mathrm{~T}\end{array}$ & $\begin{array}{l}175- \\
185 \mathrm{~B} \\
190+ \\
200-\mathrm{t} \\
190- \\
160+ \\
200-\mathrm{t} \\
190-\mathrm{t} \\
190-\mathrm{t} \\
190- \\
180+\end{array}$ & $\begin{array}{l}- \\
- \\
- \\
- \\
\overline{+} \\
- \\
- \\
- \\
- \\
+\end{array}$ & $\begin{array}{l}140- \\
130= \\
140= \\
140= \\
140= \\
125- \\
130- \\
130= \\
130- \\
125- \\
130-\end{array}$ & $\begin{array}{l}\downarrow \\
\downarrow \\
\downarrow \\
\downarrow \\
\downarrow \\
\downarrow \\
\downarrow \\
\downarrow\end{array}$ \\
\hline
\end{tabular}

Electrocardiogram: presenting abnormality, either ST segment, T wave, or both. Treadmill tests: + a positive test; - a negative test; B, borderline result; MHR, maximum heart rate; tests marked $t$ began with $\mathrm{T}$ inversion which became upright during the test, returning to the original pattern during recovery. Pacing/infusion: arrows indicate direction of induced changes on $\mathrm{T}$ wave and ST segment.

$\star$ Negative result.

and after $80 \mathrm{mg}$ oxprenolol. Because of the fast resting and maximum exercise heart rates after the betablocker (90 and 150, respectively), the test was repeated after $160 \mathrm{mg}$ oxprenolol, when the maximum heart rate was 135 and the result negative (Table).

Those tests marked $t$ in the Table began with inverted $T$ waves which became upright during the test, returning to the original pattern during recovery. In the absence of ST displacement these were classed as negative.

\section{CARDIAC CATHETERISATION}

The coronary arteriogram was normal in all subjects, and there was no evidence of impaired left ventricular contraction.

\section{PACING/INFUSION STUDIES}

Both atrial pacing and adrenaline infusion influenced the ST-T segment in the same direction. Of the 16 subjects with $T$ abnormalities, $T$ inversion was produced or increased in all (Fig. 1 and 2), with slight associated ST depression in two.

The two subjects with ST abnormalities developed or increased ST depression (Fig. 3). Of the two with combined patterns, $\mathrm{T}$ inversion alone was produced in one and both ST and T changes in the other.

This synergistic effect of adrenaline on both the $T$ wave and ST segment was striking; even when infused in doses too low to exert an effect on its own of any magnitude, it enhanced the ST-T changes pro- duced by atrial pacing in a roughly dose-related manner (Fig. 3). Furthermore, on stopping atrial pacing the time required for ST-T changes to return to control appearances was progressively longer after the higher infusion rates. The effect of pacing invariably took several beats to reach a maximum.

Propranolol blocked the influence of adrenaline and its synergism with atrial pacing in all subjects. It did not, however, influence the effect of the atrial pacing itself (Fig. 4 and 5). Atropine (administered after propranolol) on the other hand abolished or reduced the effect of pacing in seven out of the 10 in whom it was administered (Fig. 5).

\section{Discussion}

A good correlation was apparent between the abnormality in the resting electrocardiogram and the electrocardiographic pattern induced by pacing alone or with infusion (Table). In those subjects who had originally presented with isolated $\mathrm{T}$ wave abnormalities or ST changes, it was usually the T wave or ST segment, respectively, that was most sensitive to manipulation by pacing/infusion.

The effects of atrial pacing and adrenaline infusion were similar and synergistic, whether they were to produce or increase $\mathrm{T}$ wave depression and inversion or to induce ST depression. The enhancement of the effect of pacing by adrenaline was apparent even when the dose of the latter was so low as to produce only 

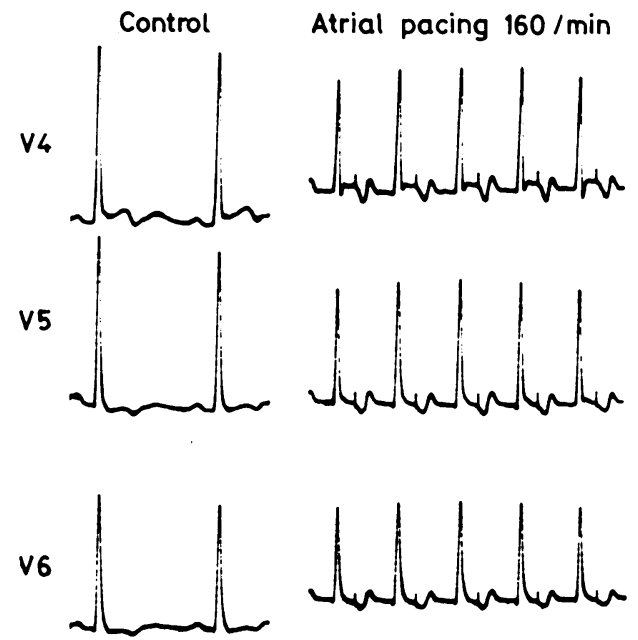

Case 3 age $18 y$

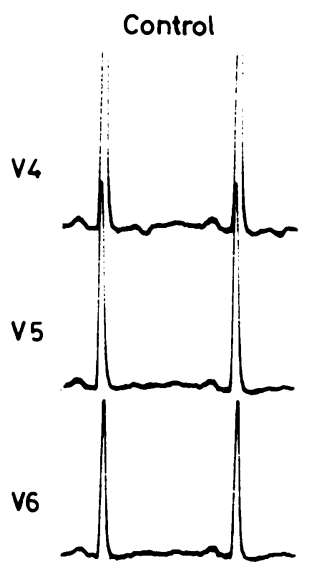

$$
\text { Atrial pacing } 160 / \mathrm{min}
$$

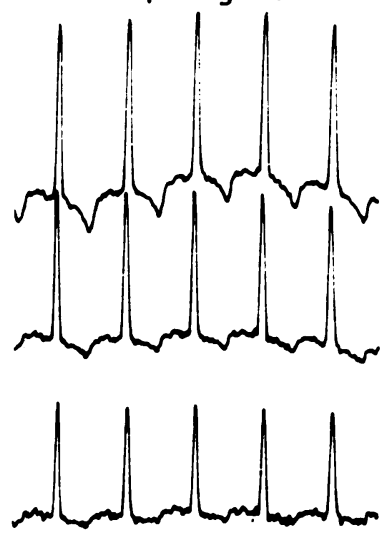

Case 5 age $28 y$

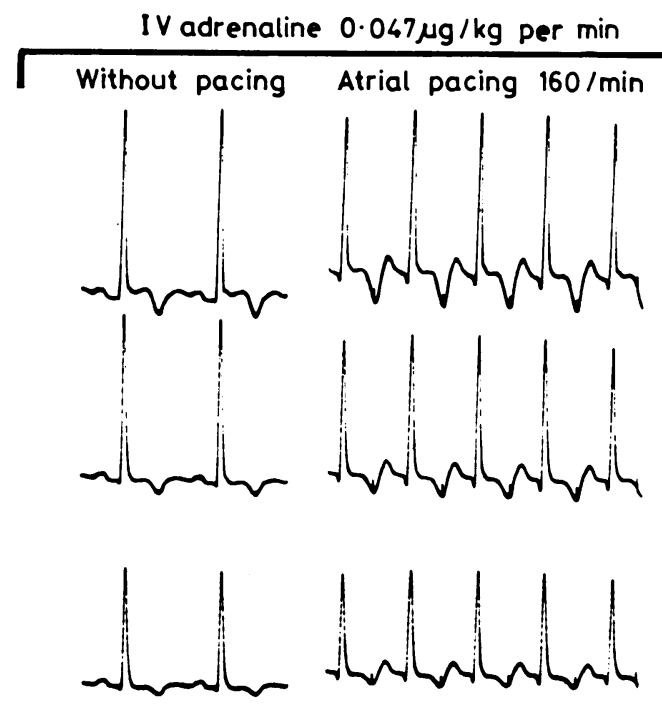

IV adrenaline $0.047 \mu \mathrm{g} / \mathrm{kg}$ per min

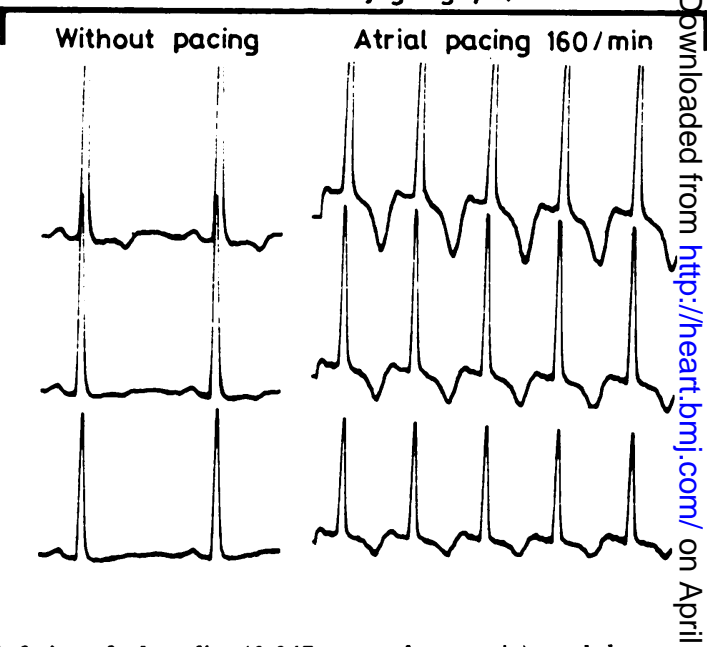

Fig. 1 and 2 Influence of atrial pacing to 160 per min, intravenous infusion of adrenaline (0.047 $\mu \mathrm{g}$ per $\mathrm{kg}$ per min), and the combination of the two on the $T$ wave of cases 3 and 5 who presented with $T$ wave changes in their resting electrocardiogram.

barely discernible changes on its own (Fig. 2 and 4). Pacing and adrenaline not only produce the same $\mathrm{T}$ wave and ST segment changes but it is also clear that they can greatly potentiate the action of each other. This potentiation might simply imply a higher nonlinear relation between the overall effect (electrocardiographic changes) and the underlying mechanism (probably differential effects on action potentials in different regions of the heart). This concept is illuseo trated in Fig. 6. Adrenaline infusion or atrial pacing్ acting via the intermediary of the underlying mechanof ism may hypothetically exert a similar but smalto response on the electrocardiogram (point a). Applied together, however, and assumed to be simply additiv\$ as far as the underlying mechanism is concerned, the may produce a much larger response (point b). It i is 


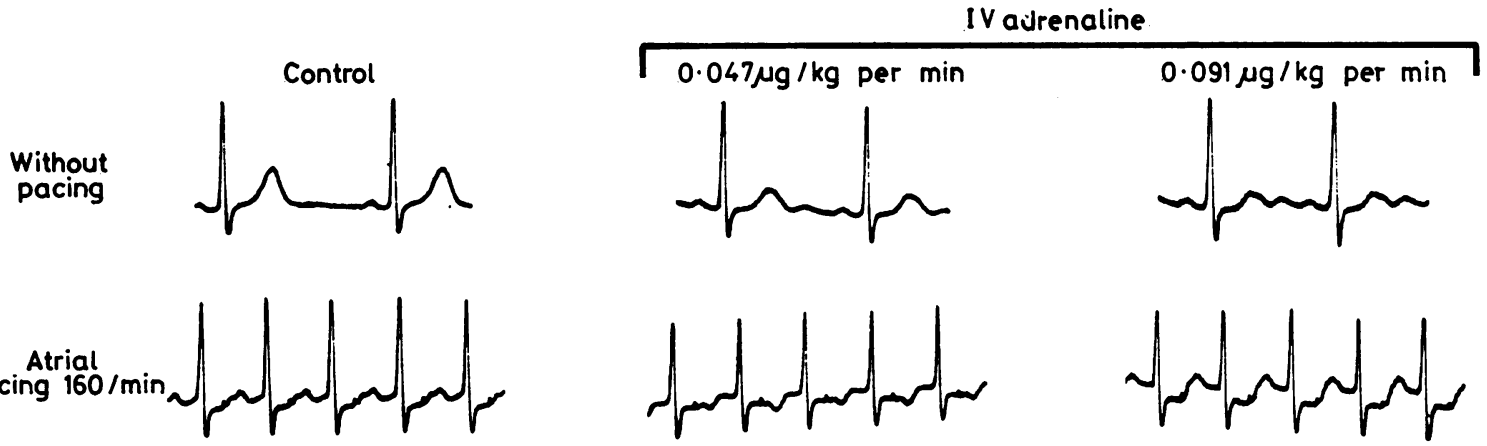

Case 1 age 53y

Fig. 3 Roughly dose related ST segment depression during atrial pacing to 160 per min in response to intravenous infusion of adrenaline in two doses (0.047 and $0.091 \mu \mathrm{g}$ per $\mathrm{kg}$ per min) in case 1 with intermittent ST segment changes in the resting electrocardiogram.

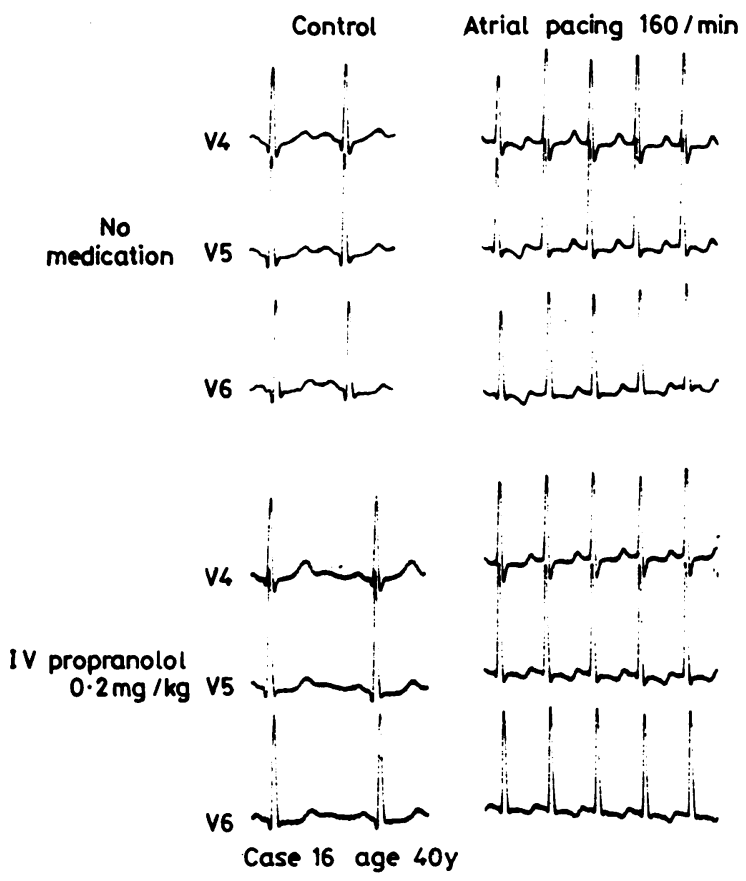

\section{IV adrenaline $0.047 \mathrm{\mu g} / \mathrm{kg}$ per min}
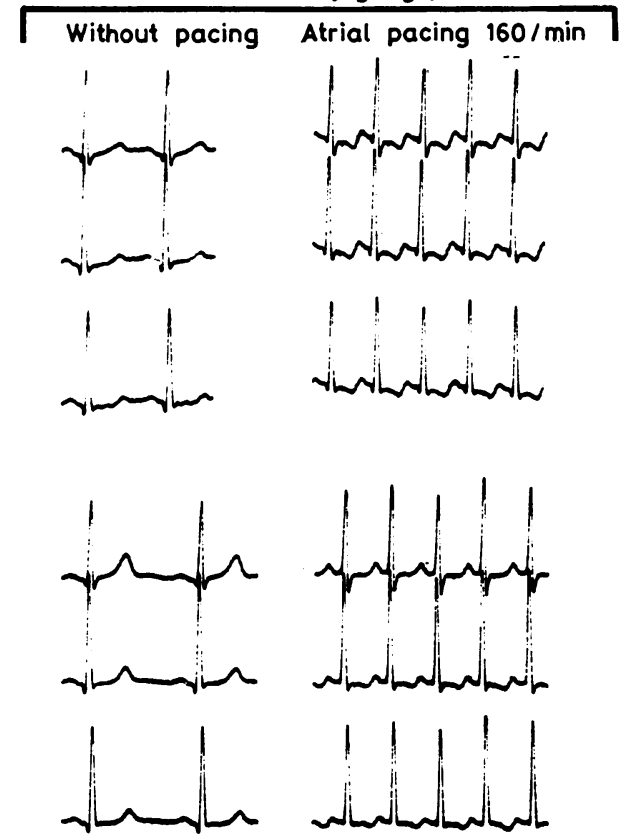

Fig. 4 The influence of atrial pacing to 160 per min (case 16), intravenous adrenaline infusion, and the combination of the two without medication (top) and after propranolol (bottom).

therefore not essential to assume that adrenaline directly potentiates the response to pacing to explain our results.

Control subjects were of necessity omitted from this study for obvious reasons. Lepeschkin and his colleagues, ${ }^{3}$ however, infusing adrenaline in a dose of 0.1 $\mu \mathrm{g} / \mathrm{kg}$ per min observed T changes in only two of $\mathbf{4 0}$ apparently healthy young men and even doses of 0.3 $\mu \mathrm{g} / \mathrm{kg}$ per min induced $\mathrm{T}$ changes in only four of 60 young women $(5.7 \%)$. ST displacement was not seen in any of their subjects. Atrial pacing per se, even when prolonged, does not influence $T$ wave polarity in normal subjects. ${ }^{4}$ In our experience $S T$ or $T$ wave changes are rare in patients undergoing routine electrophysiological studies for problems such as syncope or sinus node disease, though by no means uncom- 


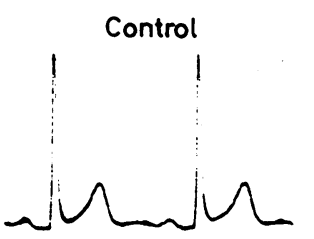

No medication
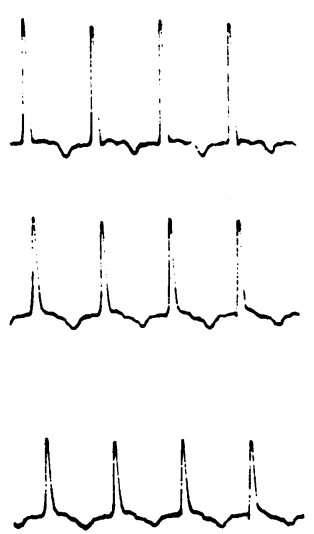

IV propranolol
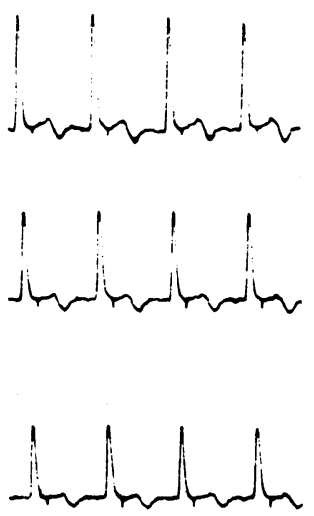

IV propranolol $+$

IV atropine
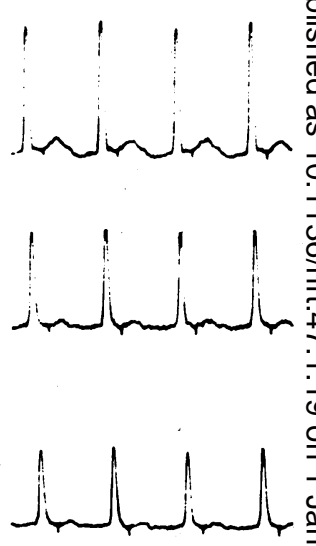

Case 17 age $29 y$

Fig. 5 The influence of atrial pacing before and after intravenous propranolol, and after intravenous propranolol and atropine in case 17.

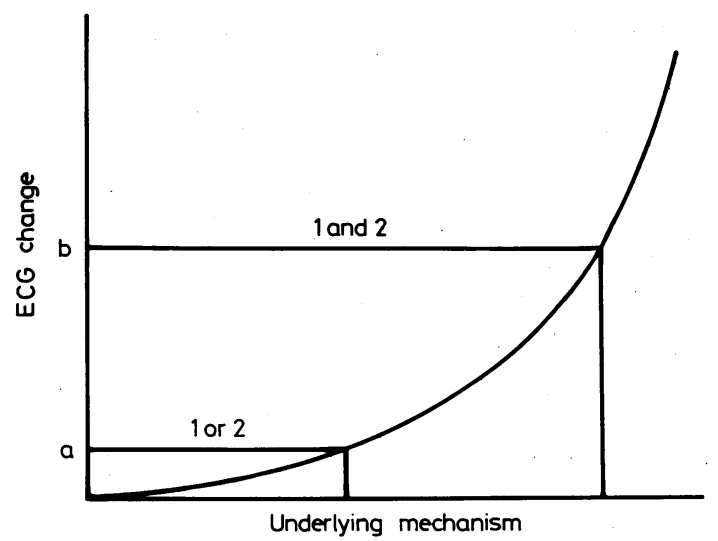

Fig. 6 The synergism between adrenaline and atrial pacing may be explained if the effect of each on pump activity is non-linear. Adrenaline infusion (1) or atrial pacing (2).

mon patients with angina or pre-excitation. We are unaware of any studies in which atrial pacing has been combined with adrenaline infusion; the lack of reference data and the absence of control subjects impose limitations on the interpretation of our results.

Propranolol blocked the effect of adrenaline alone and its potentiating effect on atrial pacing but did not influence the effect of the pacing itself. This suggests that when ST-T changes occur as a result of an increase in stimulation frequency they reflect a direct effect on the mechanisms responsible for the action potential duration gradients rather than an action mediated by the sympathetic. We cannot explain whyo atropine appeared to reduce the rate related ST-T\% changes induced by atrial pacing after propranolol $\stackrel{\Omega}{\rightarrow}$ Acetylcholine has long been known to be withoup effect on the action potentials of the mammalian ven- $\frac{3}{5}$ tricle except in enormous concentrations, ${ }^{5}$ probablye because of an increase in potassium conductance. ${ }^{6}$. Data on human ventricle, however, are lacking. It is possible that the effects of atrial pacing in these sub $\frac{N}{7}$ jects were mediated via the vagus. Our observationg that the effects of atrial pacing took several beats to reach a maximum would be consistent with as neurogenic reflex.

The false positive exercise test was common inf those with ST segment resting electrocardiographic $\$$ abnormalities, occurring in three out of four and bor을. derline in the fourth who had mixed ST segment andh $T$ wave changes in the resting tracing. It also occurred, however, in six out of $16(38 \%)$ subjects present 0 ing with pure $T$ wave abnormalities, and this is in excess of the $10 \%$ incidence expected from a randome population $^{2}$ and similar to our previous findings in comparable subjects. ${ }^{1}$

This study is in keeping with our other observa $\stackrel{0}{+}$ tions showing that if patients with asymmetricalo hypertrophy are excluded, beta-blockade will normalo ise a positive exercise test in those with angiographio cally unobstructed coronary arteries but will no马 influence or will only partially normalise a positive 
test in patients with more than $50 \%$ narrowing of at least one major vessel. ${ }^{8}$ The mechanism of this is not clear. It is certainly not simply because of the lower maximum heart rate attained on beta-blockers, since, as shown in the Table, of the nine positive and one borderline tests without beta-blockers, five were already positive and two borderline at relatively low heart rates. Similarly, it is unlikely that the positive tests were the result of disparity between oxygen supply and demand as our subjects were asymptomatic young men without coronary artery narrowing.

While it is possible that these subjects were predisposed to coronary artery spasm, we did not feel it justified to administer ergometrine during angiography. If spasm was involved, at least some subjects should have experienced classical or Prinzmetal's angina and there should have been a higher incidence of angiographically evident obstruction. ${ }^{9}$ Small vessel disease is also an unlikely explanation since it is usually associated with particular clinical characteristics such as systemic disease, ${ }^{10}$ cardiac enlargement, arrhythmias, conduction disease, and syncope, ${ }^{11}$ none of which was present in our subjects.

A more attractive explanation is that the ST depression during exercise reflects a differential effect of sympathetic activity on the plateau phase of cardiac action potentials even in normal tissue. Such explanation has been described in detail ${ }^{1}$ and is based on action potential duration gradients thought to be responsible for creating the dipole that generates the $T$ wave. Discussion, however, of the influence of action potential changes on the surface electrocardiogram $^{12}$ is beyond the scope of the present article.

As mentioned earlier, the normalisation of the false positive exercise test was not simply the result of the lower maximum heart rate achieved during the tests on beta-blockers, as in several instances tests were already positive early on during the subjects' previous tests at comparable heart rates, without beta-blockers. It might be inferred from the absence of any effect of beta-blockade on pacing-induced ST depression that the false positive exercise test is not purely rate dependent-if it were so false positive tests should not have been prevented by oxprenolol.
This study was financed by the Heart Research Fund of the Middlesex Hospital, CIBA Laboratories, and the Gallaher Charitable Foundation.

\section{References}

1 Taggart P, Carruthers M, Joseph S, et al. Electrocardiographic changes resembling myocardial ischaemia in asymptomatic men with normal coronary arteriograms. Br Heart f 1979; 41: 214-25.

2 Doan AG, Peterson DR, Blackmon JR, Bruce RA. Myocardial ischemia after maximal exercise in healthy men. A method for detecting potential coronary heart disease? Am Heart $f$ 1975; 69: 11-21.

3 Lepeschkin E, Marchet H, Schroeder G, et al. Effect of epinephrine and norepinephrine on the electrocardiogram of 100 normal subjects. Am $\mathcal{F}$ Cardiol 1960; 5: 594-603.

4 Chatterjee K, Harris A, David G, Leatham A. Electrocardiographic changes subsequent to ventricular depolarization. Br Heart $\mathcal{F}$ 1969; 31: 770-9.

5 Hoffman BF, Suckling EE. Cardiac cellular potentials: effect of vagal stimulation and acetylcholine. Am $\mathcal{J}$ Physiol 1953: 173: 312-20.

6 Hutter OF. Mode of action of autonomic transmitters on the heart. Br Med Bull 1957; 13: 176-80.

7 Noble D. The initiation of the heart beat. Oxford: Clarendon Press, 1975.

8 Marcomichelakis J, Donaldson R, Green J, et al. Exercise testing and beta-blockade: improved specificity and predictive value in detecting coronary heart disease. $\mathrm{Br}$ Heart $\mathcal{F}$ 1980; 43: 252-61.

9 Selzer A. Cardiac ischemic pain in patients with normal coronary arteriograms. Am F Med 1977; 63: 661-5.

10 Bulkley BH, Klacsmann PG, Hutchins GM. Angina pectoris, myocardial infarction and sudden cardiac death with normal coronary arteries. A clinicopathologic study of 9 patients with progressive systemic sclerosis. $\mathrm{Am}$ Heart F 1978; 95: 563-9.

11 James TN. Pathology of small coronary arteries. Am f Cardiol 1967; 20: 679-91.

12 Holland RP, Arnsdorf MF. Solid angle theory and the electrocardiogram: physiologic and quantitative interpretations. Prog Cardiovasc Dis 1977; 19: 431-57.

Requests for reprints to Dr P Taggart, Department of Cardiology, The Middlesex Hospital, Mortimer Street; London W1N 8AA. 